\title{
Does Metabolic Syndrome or its Components Correlate With Lower Urinary Tract Symptoms in Benign Prostatic Hyperplasia Patients?
}

\author{
Onur Telli ${ }^{1, *}$; Arif Demirbas ${ }^{1}$; Mucahit $\operatorname{Kabar}^{1}$; Mehmet Ali Karagoz ${ }^{1}$; Hasmet Sarici ${ }^{1}$; Berkan \\ Resorlu $^{1}$ \\ ${ }^{1}$ Department of Urology, School of Medicine, Ankara University, Ankara, Turkey \\ *Corresponding author: Onur Telli, Department of Urology, School of Medicine, Ankara University, Ankara, Turkey. Tel: +90-5065987517, E-mail: onurtelli@yahoo.com
}

Received: February 11, 2015; Accepted: March 12, 2015

\begin{abstract}
Background: Metabolic Syndrome (MS) has become a global public health and has been suggested to be a risk factor for Lower Urinary Tract Symptoms (LUTS). Studies evaluating the association between the rate of the MS and LUTS often showed controversial results.

Objectives: The purpose of this study was to reveal the relevance of MS and its components on the frequency and severity of the LUTS that were seen with Benign Prostate Hyperplasia (BPH) in Turkish men or not.

Patients and Methods: In this study, 237 patients referred to urology policlinic with BPH were retrospectively scanned between April 2009 and April 2013. Patients with normal digital rectal examination and the Prostate Specific Antigen (PSA) level of $\leq 4 \mathrm{ng} / \mathrm{mL}$ were evaluated using the International Prostate Symptom Score (IPSS) and all the data of the patients' body, including Body Mass Index (BMI), lipid parameters, preprandial blood glucose, and waist circumference. Seventy-four patients (31.3\%) with mild IPSS (0-7) was group 1; 97 patients (40.9\%) with moderate IPSS (8 - 19) group 2 and 66 patients (27.8\%) with severe IPSS (20-35) were defined as group 3. group 4 consisted of 117 healthy controls. Three groups and controls were compared about MS and its components. The diagnosis criteria of The Society of Endocrinology and Metabolism of Turkey were used in MS diagnosis. Also, BMI, lipid parameters, preprandial blood glucose, waist circumference, and blood pressure were used as MS parameters.

Results: The average age of patients in group 1 was $69.8 \pm 7.2$; in group $2,69.1 \pm 7.4 ; 68.3 \pm 7.1$ in group 3 and $70.2 \pm 7.2$ in the control group. Metabolic syndrome was determined at 37 patients (50\%) in group 1, 45 patients (46.5\%) in group 2, 32 patients (48\%) in group 3 and 52 patients (44.4\%) in controls and no statistically significant correlation was detected between LUTS and MS in BPH (P = 0.113). In the comparison of the four groups in the point of MS parameters, no significant correlation was detected in the levels of total cholesterol $(\mathrm{P}=$ 0.337), fasting glucose $(\mathrm{P}=0.291)$, $\mathrm{BMI}(\mathrm{P}=0.452)$, Low Density Lipoprotein (LDL, $\mathrm{P}=0.069)$ and triglyceride $(\mathrm{P}=0.307)$.

Conclusions: In our study, the evidence is not enough to support the hypothesis of the relevance between MS and LUTS. Wide-ranging, prospective and multicentric studies are needed to research the relevance between MS and LUTS in BPH.
\end{abstract}

Keywords: Lower Urinary Tract Symptoms; Metabolic Syndrome; Prostatic Hyperplasia

\section{Background}

There is a high prevalence of Metabolic Syndrome (MS), which is comprised of insulin resistance, obesity, hypertension, and high levels of blood glucose and lipids (1). Metabolic syndrome is thought to affect male prostate growth, and correlations between severity of male Lower Urinary Tract Symptoms (LUTS) and MS components have been reported $(2,3)$. On the other hand, previous studies indicate that MS is not independently associated with either the pathogenesis or severity of LUTS in healthy middle-aged and elderly men $(4,5)$. Additionally, some studies suggested no positive association between MS and male LUTS, the impact of metabolic factors on male LUTS remained inadequate $(6,7)$ and the early stage of hyperinsulinemia may actually have a favorable effect on male LUTS (8). Although the hypothesis of the role of MS in the etiology of BPH remains unclear, the epidemiological evidences are insufficient to suggest a link between MS and LUTS in BPH. Most previous studies on the relationship between MS and BPH were conducted in multiracial groups or non-Turkish populations.

\section{Objectives}

In this study, we aimed to investigate the relationship between MS and LUTS in BPH in Turkish men.

\section{Patients and Methods}

We reviewed the records of 1302 patients who admitted to outpatient clinics with a serum Prostate-Specific Antigen (PSA) level $\leq 4 \mathrm{ng} / \mathrm{mL}$ and normal digital rectal examination at a main training and research hospital between February 2009 and April 2013. Patients with a history of prostate cancer or prostatic surgery, or whose data were insufficient for analysis were excluded. Two

Copyright ( ) 2015, Nephrology and Urology Research Center. This is an open-access article distributed under the terms of the Creative Commons Attribution-NonCommercial 4.0 International License (http://creativecommons.org/licenses/by-nc/4.0/) which permits copy and redistribute the material just in noncommercial usages, provided the original work is properly cited. 
Telli $O$ et al.

\begin{tabular}{|c|c|c|c|c|c|}
\hline & Group 1 (IPSS: 0 - 7) & Group 2 (IPSS: 8 - 19) & Group 3 (IPSS: 20 - 35) & Group 4 (Control) & P Value \\
\hline Metabolic Syndrome/Yes & $37(50)$ & $45(46.3)$ & $32(48.4)$ & $52(44.4)$ & 0.172 \\
\hline Metabolic Syndrome/No & $37(50)$ & $52(53.7)$ & $34(51.6)$ & $65(55.6)$ & 0.094 \\
\hline \multicolumn{6}{|c|}{$\begin{array}{l}\text { a Abbreviation: IPSS, International prostate symptom score. } \\
\text { b Data are presented as No. (\%). }\end{array}$} \\
\hline & Group 1 & Group 2 & Group 3 & Group 4 & P Value \\
\hline Age, y & $69.8 \pm 7.2$ & $69.1 \pm 7.4$ & $68.3 \pm 7.1$ & $70.2 \pm 7.2$ & 0.144 \\
\hline BMI, kg/m² & $27.77 \pm 2.85$ & $26.45 \pm 3.02$ & $26.33 \pm 2.79$ & $28.04 \pm 2.82$ & 0.452 \\
\hline Fasting glucose, $\mathrm{mg} / \mathrm{dL}$ & $122.1 \pm 27.37$ & $133.6 \pm 33.31$ & $130.8 \pm 39.04$ & $121.07 \pm 49.08$ & 0.291 \\
\hline Total cholesterol, mg/dL & $190.9 \pm 7.47$ & $187.8 \pm 9.69$ & $194.6 \pm 7.84$ & $190.9 \pm 7.47$ & 0.337 \\
\hline Triglyceride, mg/dL & $155.6 \pm 40.3$ & $156.1 \pm 42.6$ & $152.6 \pm 41.4$ & $142.53 \pm 42.3$ & 0.307 \\
\hline LDL cholesterol, mg/dL & $123.6 \pm 17.4$ & $132.4 \pm 21.5$ & $125.7 \pm 22.2$ & $122.85 \pm 30.2$ & 0.069 \\
\hline
\end{tabular}

a Abbreviations: BMI, body mass index; LDL, low-density lipoprotein.

$\mathrm{b}$ Data are presented as mean \pm SD.

hundred and thirty-seven patients with LUTS in BPH met our inclusion criteria and were enrolled in the study. Group 1 consisted of 74 patients with mild International Prostate Symptom Score (IPSS) (0-7); group 2 consisted of 97 patients with moderate IPSS ( 8 - 19); group 3 consisted of 66 patients with severe IPSS (20 - 35) and group 4 consisted of 117 healthy controls of adult normal population, whom underwent medical check-ups at the same hospital and without any history of LUTS. All patients received a physical examination including measurement of height, weight, and waist circumference $(2 \mathrm{~cm}$ above umbliculus). Body Mass Index (BMI) was computed according to Quetelet's index [weight/height $\left.{ }^{2}\left(\mathrm{~kg} / \mathrm{m}^{2}\right)\right]$. The indicator of MS was defined according to Association of Turkish Endocrinology and Metabolism, Metabolic Syndrome Diagnostic Criteria (9), as the presence of at least one component among following: diabetes mellitus or impaired glucose tolerance or glucose resistance and at least two components among following: high blood pressure $(130 / 85 \mathrm{mmHg}$ ) or use of antihypertensive drugs, dyslipidemia [triglyceridemia $(150 \mathrm{mg} / \mathrm{dL})$ or reduced HDL cholesterol $(<40 \mathrm{mg} / \mathrm{dL}$ )] or abdominal obesity (abdomen circumference $>94 \mathrm{~cm}$ or BMI $>30 \mathrm{~kg} / \mathrm{m}^{2}$ ).

All statistical analyses were performed using SPSS v.16.5 (SPSS Inc., Chicago, Illinois, USA). All values were expressed as Mean \pm Standard Error (SEM). The variables were investigated using the visual (histograms probability plots) and analytical methods (the Kolmogorov-Simirnov test) to determine whether or not they are normally distributed. Descriptive statistics were reported as the mean or median with standard deviation. Unpaired t-tests were performed for data with normal distribution. For parameters that did not show normal distribution, the nonparametric MannWhitney U test was used to compare. Between groups, analyses were performed using chi-square test and P value $<0.05$ was set for statistical significance.

\section{Results}

From a total of 166 patients, 37 cases in group 1 (mild IPSS: 0-7); 45 cases in group 2 (moderate IPSS: 8-19); 32 cases in group 3 and 52 controls in group 4 were diagnosed with MS according to Turkish Endocrinology Metabolism, Metabolic Syndrome Diagnostic Criteria and there was no significant difference between the experimental groups and control group in association between MS and LUTS (Table 1). Mean age of the patients was $69.8 \pm 7.2$ years in group 1; 69.1 \pm 7.4 years in group $2 ; 68.3 \pm 7.1$ in group 3 and $70.2 \pm 7.2$ in controls $(\mathrm{P}=0.144)$. There was no significant difference in MS and its components including BMI $(P=0.452)$, fasting glucose $(P=0.291)$, triglyceride $(P$ $=0.307)$, LDL-cholesterol $(\mathrm{P}=0.069)$ and total cholesterol $(\mathrm{P}=0.337)$ between the groups. Baseline characteristics of the groups with MS and controls with MS are presented in Table 2.

\section{Discussion}

Epidemiologic studies of different populations have been demonstrated to identify the risk factors for male LUTS in BPH. These studies have reported a relationship among LUTS, MS, and lifestyle-related diseases caused by a lack of exercise, drinking, smoking, obesity, hypertension, hyperlipidemia, and cardiovascular disease $(10,11)$. In the present study the relationships between the rates of mild, moderate or severe LUTS and MS were evaluated and no significant association was found between the MS and the presence of LUTS compared to the controls without LUTS.

Metabolic syndrome has effects on urinary system as the many other systems. It has been considered the relationship between MS and the severity and frequency of LUTS (12). The explanation for the association of voiding and storage symptoms with MS includes the pathophysiological mechanisms with regard to atherosclerosis (13). 
The role of atherosclerosis is an important phenomenon in the aging process and poorly understood in the pathogenesis of LUTS (14). Alternative hypotheses include pelvic atherosclerosis leading to chronic ischemia of the bladder, penis, and prostate, which may result in impairment of LUTS (15).

The issue of association between LUTS and MS has been an area of some controversy. Similar to the present study, data from longitudinal epidemiologic studies have shown no association between anthropometric measurements, hypertension, or history of diabetes with development of clinical BPH $(16,17)$. Temml and colleagues reported no positive associations between MS and total IPSS, storage and voiding score, or LUTS. It was suggested that nicotine use and other factors that increase sympathetic nervous system activity might contribute to LUTS (18). Additionally, in a recent study, it was reported that Asian men had less prostate progression and lower LUTS scores compared to men in the west; a finding which may be explained by a different diet and lifestyle (4). In a previous study, it was suggested that MS was not associated with LUTS due to the small number and narrow age range of the subjects and a lack of understanding of the IPSS questions by the elderly subjects.

In our study, we did not analyze the extensive analyses because of the relatively small number of sample size with lack of information, which is the major limitation of retrospective review. Another limitation of the study was that the specific diabetic medications were not collected from the participants. This could be an important confounding variable, which could be an important aspect of evaluating MS and LUTS risk in future studies to confirm the exact role of cholesterol and other blood lipids in development and progression of BPH.

In conclusion, we found little evidence to support the hypothesis that MS or its components explain association between MS and LUTS in BPH. The association between the different fractions of cholesterol and prostate cancer needs to be confirmed in larger, prospective studies.

\section{Authors' Contributions}

Study concept and design: Onur Telli, and Arif Demirbas. Acquisition of data: Mehmet Ali Karagoz, Mucahit Kabar, and Arif Demirbas. Analysis and interpretation of data: Onur Telli, and berkan Resorlu. Drafting of the manuscript: Onur Telli and Hasmet Sarici. Critical revision of the manuscript for important intellectual content: Onur Telli. Statistical analysis: Onur Telli, and Hasmet Sarici. Administrative, technical, and material support: Mehmet Ali Karagoz, Mucahit Kabar, and Arif Demirbas. Study supervision: Onur Telli, and Berkan Resorlu.

\section{References}

1. Lakka HM, Laaksonen DE, Lakka TA, Niskanen LK, Kumpusalo E, Tuomilehto J, et al. The metabolic syndrome and total and cardiovascular disease mortality in middle-aged men. JAMA. 2002;288(21):2709-16

2. Kupelian V, McVary KT, Kaplan SA, Hall SA, Link CL, Aiyer LP, et al. Association of lower urinary tract symptoms and the metabolic syndrome: results from the Boston Area Community Health Survey.J Urol. 2009;182(2):616-24.

3. Rohrmann S, Smit E, Giovannucci E, Platz EA. Association between markers of the metabolic syndrome and lower urinary tract symptoms in the Third National Health and Nutrition Examination Survey (NHANES III). Int J Obes (Lond). 2005;29(3):3106.

4. Ohgaki K, Hikima N, Horiuchi K, Kondo Y. Association between metabolic syndrome and male lower urinary tract symptoms in Japanese subjects using three sets of criteria for metabolic syndrome and International Prostate Symptom Score. Urology. 2011;77(6):1432-8.

5. Park HK, Lee HW, Lee KS, Byun SS, Jeong SJ, Hong SK, et al. Relationship between lower urinary tract symptoms and metabolic syndrome in a community-based elderly population. Urology. 2008;72(3):556-60.

6. Hong GS, Shim BS, Chung WS, Yoon H. Correlation between Metabolic Syndrome and Lower Urinary Tract Symptoms of Males and Females in the Aspect of Gender-Specific Medicine: A Single Institutional Study. Korean JUrol. 2010;51(9):631-5.

7. Gao Y, Wang M, Zhang H, Tan A, Yang X, Qin X, et al. Are metabolic syndrome and its components associated with lower urinary tract symptoms? Results from a Chinese male population survey. Urology. 2012;79(1):194-201.

8. Eom CS, Park JH, Cho BL, Choi HC, Oh MJ, Kwon HT. Metabolic syndrome and accompanying hyperinsulinemia have favorable effects on lower urinary tract symptoms in a generally healthy screened population. J Urol. 2011;186(1):175-9.

9. Arslan, M. , Atmaca, A., Ayvaz, G., Bașkal, N. , Beyhan, Z., Bolu, E. 2. Vol. 5. Metrix matbaacilı, Istanbul: Turkiye Endokrinoloji ve Metabolizma Hastalıkları Dernegi, Metabolik Sendrom Calısma Grubu; 2007. Metabolik Sendrom Kılavuzu.

10. Ponholzer A, Temml C, Wehrberger C, Marszalek M, Madersbacher $\mathrm{S}$. The association between vascular risk factors and lower urinary tract symptoms in both sexes. Eur Urol. 2006;50(3):581-6.

11. Wong SY, Woo J, Hong A, Leung JC, Kwok T, Leung PC. Risk factors for lower urinary tract symptoms in southern Chinese men. Urology. 2006;68(5):1009-14.

12. Moul S, McVary KT. Lower urinary tract symptoms, obesity and the metabolic syndrome. Curr Opin Urol. 2010;20(1):7-12.

13. Nomiya M, Sagawa K, Yazaki J, Takahashi N, Kushida N, Haga N, et al. Increased bladder activity is associated with elevated oxidative stress markers and proinflammatory cytokines in a rat model of atherosclerosis-induced chronic bladder ischemia. Neurourol Urodyn. 2012;31(1):185-9.

14. Pinggera GM, Mitterberger M, Steiner E, Pallwein L, Frauscher F, Aigner F, et al. Association of lower urinary tract symptoms and chronic ischaemia of the lower urinary tract in elderly women and men: assessment using colour Doppler ultrasonography. BJU Int. 2008;102(4):470-4.

15. Shimizu S, Tsounapi P, Shimizu T, Honda M, Inoue K, Dimitriadis $\mathrm{F}$, et al. Lower urinary tract symptoms, benign prostatic hyperplasia/benign prostatic enlargement and erectile dysfunction: are these conditions related to vascular dysfunction? Int J Urol. 2014;21(9):856-64.

16. Burke JP, Rhodes T, Jacobson DJ, McGree ME, Roberts RO, Girman $\mathrm{CJ}$, et al. Association of anthropometric measures with the presence and progression of benign prostatic hyperplasia. Am J Epidemiol. 2006;164(1):41-6.

17. Meigs JB, Mohr B, Barry MJ, Collins MM, McKinlay JB. Risk factors for clinical benign prostatic hyperplasia in a community-based population of healthy aging men. J Clin Epidemiol. 2001;54(9):935-44.

18. Temml C, Obermayr R, Marszalek M, Rauchenwald M, Madersbacher S, Ponholzer A. Are lower urinary tract symptoms influenced by metabolic syndrome? Urology. 2009;73(3):544-8. 